\title{
CRITÉRIOS PARA A SELEÇÃO DE CANDIDATOS AO CURSO DE DOUTORADO
}

\author{
Maria Romana Friedlander * \\ Maria Gaby Rivero de Gutierrez ** \\ Massae Noda **
}

Uma das mais prementes preocupações das escolas de enfermagem brasileiras, na atualidade, é a qualificação do seu corpo docente e, conseqüentemente, a titulação acadêmica. Por outro lado, a área assistencial, pressionada pelos avanços científicos, precisa qualificar seus líderes e, inevitavelmente, começará a valorizar a titulação daqueles que pretendem assumir posições de destaque e chefia na prática profissional.

A rápida evolução da profissão está, de certa forma, associada à quantidade e qualidade dos cursos de Pós-Graduação "stricto sensu" uma vez que, subjacente aos seus currículos, está implícito o desenvolvimento de certas competências e capacidades cognitivas bem como a convivência temporária num ambiente de trabalho estimulador e rico em experiências compatíveis com as futuras funções e encargos (STEFANELLI \& FRIEDLANDER, 1992).

O doutorado em enfermagem que, nos Estados Unidos, forma doutores para assumirem funções na área assistencial (LASH, 1987; SNYDER-HALPERN, 1987; MELEIS, 1988), constitui o nível de formação mais avançado no Brasil e, tem como objetivos, a formação de pesquisadores, professores e líderes profissionais. Portanto, selecionar candidatos para esse curso é um processo que exige reflexão para o estabelecimento de critérios coerentes com as finalidades do mesmo.

* Professor Livre-Docente Visitante do Departamento de Enfermagem da Universidade Federal de São Paulo

** Professor Doutor do Departamento de Enfermagem da Universidade Federal de São Paulo 
Como a tendência no Brasil é a abertura de novos cursos de Doutorado, a divulgação de alguns critérios e as justificativas para a sua adoção podem originar uma discussão de grande utilidade para aqueles que assumem essa responsabilidade. Assim, este trabalho tem como objetivo descrever os critérios que usamos bem como as justificativas de os termos adotado para que possam servir de base a outros docentes com encargos similares. Por outro lado, a divulgação dessa experiência permite a sua crítica e, conseqüentemente, seu aperfeiçoamento.

O fato de termos participado por inúmeras vezes de comissões encarregadas de selecionar os candidatos para admissão aos cursos de doutorado estimulou-nos a refletir sobre as conseqüências, principalmente mediatas, dessa tarefa e é a partir dessa reflexão que descrevemos as nossas decisões.

Em princípio, a formulação dos critérios em questão exige grande clareza nos objetivos do curso. Assim, os critérios aqui descritos partiram das seguintes premissas:

- o programa de doutorado para o qual se faz a seleção visa o desenvolvimento de competências para a pesquisa acadêmica e clínica com vistas à evolução do conhecimento teórico e prático de enfermagem;

- esse programa objetiva, também, o desenvolvimento de competências relacionadas à docência e à liderança nas áreas de ensino, pesquisa e assistência em enfermagem.

Portanto, selecionar candidatos para esses cursos significa escolher aqueles que irão, no futuro, delinear os principais caminhos da profissão e poderão liderar os principais movimentos da Enfermagem, os quais, necessariamente, repercutirão na própria identidade profissional. Não se trata de presente a ser oferecido a quem fez algo para merecer, mas assumir a responsabilidade por pensar, hoje, no amanhã da profissão. As instituições que estão pretendendo qualificar seus docentes devem, também, preocupar-se com os critérios para a concessão de licenças e afastamentos financiados com a finalidade de obtenção de títulos para que garantam o retorno eficaz do investimento realizado.

Geralmente, a primeira etapa da seleção consiste na definição do processo dessa seleção (como, quando, onde e quem) bem como no que se vai exigir do candidato no momento de sua inscrição. O "curriculum vitae" é freqüentemente exigido, pois pode fornecer informações valiosas sobre o dinamismo, a formação, a experiência e a produção do futuro doutorando. Pelo curriculum, o selecionador pode perceber se o doutorado é fruto de um projeto de vida (ZIEMER, et al, 1992) ou constitui um evento acidental no percurso profissional do candidato. Outra exigência comum é a apresentação de um projeto detalhado de pesquisa de autoria do candidato, que demonstra sua capacidade de planejar uma investigação, bem como a profundidade do seu conhecimento sobre o tema escolhido e a metodologia 
conhecimento sobre o tema escolhido e a metodologia selecionada para a investigação. Esta exigência parece coerente com as finalidades do curso e oferece informações, também, sobre a capacidade de expressão escrita do futuro líder profissional ou docente qualificado para formar enfermeiros.

Finalmente, é planejada uma entrevista de todos os inscritos com a finalidade dos membros encarregados da seleção obterem dados sobre a capacidade do candidato de expressar oralmente suas idéias, seu poder de argumentação, a profundidade de seu conhecimento sobre os referenciais do conteúdo e da metodologia constante de seu projeto e as explicações oferecidas para alguns eventos ou acontecimentos, apontados em seu "curriculum vitae", que suscitaram dúvida.

A segunda fase da seleção consiste no estabelecimento de critérios para orientar o processo de julgamento dos três requisitos: o "curriculum vitae", o projeto de pesquisa e a entrevista. O ideal é dar a conhecer aos candidatos, antecipadamente, com a maior transparência e seriedade, os critérios e os procedimentos que serão adotados para a seleção e, desta forma, oferecer-lhes a oportunidade de se auto-avaliarem e optarem por se submeterem, ou não, à seleção.

A partir de nossa experiência, sugerimos um sistema de pontuação para facilitar o processo de julgamento e oferecer parâmetros comparativos entre os candidatos, possibilitando a sua classificação. Nota-se que essa pontuação somente tem valor para compararem-se os candidatos e facilitar a seleção. Não deve ser confundida com um índice de competência, pois esta contusão poderia trazer conseqüências desastrosas e injustas.

No que se relaciona ao "curriculum vitae" de cada candidato, podem ser considerados os aspectos que relatamos a seguir.

a) Tempo de formado do candidato. Este dado é referência para se verificar o dinamismo na atualização e produção científica do pretendente, bem como para se ter idéia do tempo legal que terá para produzir, assumir responsabilidades, adquirir experiência nas futuras funções e formar novos pesquisadores. Este item, servindo apenas como referência, não é pontuado.

b) Formação pós-graduada. Este dado demonstra o grau de interesse do profissional pela sua educação permanente. Podem ser pontuados os cursos de especialização do candidato da seguinte forma - quem tem um curso de especialização reconhecido recebe um ponto e quem tem dois ou mais cursos, recebe dois pontos. A pontuação referente ao mestrado depende do valor atribuído pela instituição a essa titulação (ZIEMER et al, 1992). No caso de ser uma exigência para a candidatura ao doutorado para todos os candidatos, não há necessidade de ser pontuada, uma vez que não servirá como parâmetro de comparação. Se não for exigência regimental, mas requisito altamente valorizado pode receber, como por exemplo, de 15 a 20 pontos, dependendo da área do conhecimento onde o mestrado foi realizado fora da enfermagem não precisa, obrigatoriamente, diminuir o seu mérito (FRIEDLANDER \& STEFANELLI, 1992).

c) Dinamização de atualização em função dos anos de formado. Este atributo pode ser avaliado por meio de uma taxa produzida pelo número de cursos de atualização cultural assistidos pelo pretendente, somado ao número de eventos 
(congressos, seminários, encontros e outros similares) que contam com a participação do candidato. Esta soma dividida pelo número de anos de formado, resulta no que denominamos "taxa de dinamismo de atualização" que se tem mostrado de grande utilidade para comparação entre os candidatos. Percebe-se, nitidamente, que existem candidatos muitos dinâmicos e interessados em sua constante atualização profissional, enquanto alguns valorizam outros aspectos da vida pessoal. Uma taxa alta neste atributo é considerada bastante interessante, se quisermos dar preferência a futuros líderes, preocupados com a modernidade da profissão e suficientemente dinâmicos para atuarem de forma a valorizar a capacidade de atualização e a promoção de estímulos para os demais profissionais. A pontuação recebida pelo candidato pode ser determinada da seguinte forma:

taxas de 0 até 1,9 recebem 1 ponto

taxas de 2 até 2,9 recebem 2 pontos

taxas de 3 até 3,9 recebem 3 pontos

taxas de 4 ou mais alta recebem 4 pontos

A quantidade de pontos que o candidato recebe, neste item, pode ser multiplicada por dois com a finalidade de valorizar este aspecto nos futuros doutorandos.

d) Experiência profissional. Este item foi subdividido em três subitens: experiência em ensino, na assistência e em atividades administrativas.

- No que se refere ao ensino, levanta-se o número de anos de experiência em ensino e pontua-se a experiência em ensino superior. O número de pontos é distribuído da seguinte forma:

experiência eventual em ensino superior $=0$ pontos

de 1 a 3 anos de experiência $=1$ ponto

de 4 a 7 anos de experiência $=2$ pontos

de 8 a 11 anos de experiência $=3$ pontos

mais de 11 anos $=4$ pontos

Considerando as finalidades do doutorado e a premente necessidade da qualificação docente no país, este resultado pode ser multiplicado por dois. A rápida formação de novos doutores para a docência terá, como conseqüência, a possibilidade, a prazo mais curto, de expansão deste nível educacional.

- Em relação à experiência na área assistencial, os pontos podem ser atribuídos da seguinte maneira:

* até 5 anos de experiência na assistência $=2$ pontos

* mais de 5 anos $=4$ pontos

- No que diz respeito à administração na área de ensino a pontuação foi atribuída como segue:

* experiência variada no ensino médio e superior = 2 pontos

* experiência na coordenação de cursos de especialização ou participação efetiva em disciplinas de mestrado $=4$ pontos 
e) Produção científica. Este atributo é avaliado sob três aspectos:

- Em relação à coerência na linha de atividades, verificam-se os conteúdos dos cursos assistidos, tanto de atualização como os pós-graduação e pontua-se, de $\mathrm{O}$ a 4 pontos, conforme a existência, ou não, de coerência desses cursos entre si e com a produção científica do candidato. Essa pontuação espelha a opinião dos elementos responsáveis pela seleção porque é difícil o estabelecimento de critérios quantitativos para esse atributo.

- Em relação à produção propriamente dita, só são levados em consideração os trabalhos e outras atividades dos últimos 5 anos, exceto a elaboração de manuais, a participação em capítulo(s) de livro(s) e a produção de livros, os quais recebem 1 ponto para cada atividade. Os trabalhos efetivamente divulgados em eventos e realmente publicados em revistas ou outros (se forem artigos completos), recebem a seguinte pontuação:

$$
\begin{aligned}
& \text { de } 1 \text { a } 2 \text { trabalhos }=1 \text { ponto } \\
& \text { de } 3 \text { a } 4 \text { trabalhos }=2 \text { pontos } \\
& \text { de } 5 \text { a } 6 \text { trabalhos }=3 \text { pontos } \\
& \text { mais de } 6 \text { trabalhos completos nos últimos } 5 \text { anos }=4 \text { pontos }
\end{aligned}
$$

Nota-se que não são considerados como trabalhos científicos àqueles realizados no final dos cursos de especialização e mestrado, a não ser que tenham sido transformados em artigos e divulgados. Essa produção, ligada à obtenção de títulos, já foi pontuada no momento da avaliação da formação pós-graduada.

- O candidato com experiência em orientação de trabalhos científicos, seja em nível de graduação, seja em nível de especialização recebe 1 ponto.

A soma dos pontos recebidos em todos os itens da produção científica é multiplicada por três. Esta ponderação visa valorizar os candidatos que se preocupam em produzir cientificamente, que tenham adquirido experiência e demonstrem interesse científico. São candidatos, possivelmente, com maior inclinação para o desenvolvimento do conhecimento, portanto, com um perfil adequado às futuras responsabilidades dos doutores.

f) Tempo para a aposentadoria. A partir do número de anos de formado e considerando o tempo de experiência no ensino ou na assistência.há possibilidade de se estimar aproximadamente o tempo que o candidato tem para se aposentar. dentro dos atuais parâmetros legais. A pontuação deste atributo pode ser distribuída da seguinte forma:

- se, no momento da entrevista, faltar menos de um ano para o candidato aposentarse, não recebe nenhum ponto;

- se faltar de 1 a 3 anos, recebe 1 ponto;

- se faltar de 4 a 6 anos, recebe 2 pontos;

- se faltar de 7 a 9 anos, recebe 3 pontos; e

- se faltar 10 anos ou mais, recebe 4 pontos.

Esta pontuação visa valorizar o trabalho desenvolvido pelos cursos titular profissionais que tenham condições de formar novos doutores, antes de completar o tempo regulamentar para aposentar-se. Isto significa, aproximadamente, 12 anos 
pois, para que um doutor, após se titular, em período previsto de 4 anos, possa formar novos doutores, é necessário ter currículo compatível com o de orientador, neste nível e desenvolver a tarefa de orientar por pelo menos, 4 anos.

Sem propriamente impedir que profissionais com maior tempo de serviço adquiram seu título de doutor, este critério procura proteger o futuro da enfermagem, garantindo e consolidando sua continuidade como profissão liberal, seu desenvolvimento como ciência e a qualidade dos serviços prestados à sociedade. E importante acrescentar que este critério terá que ser revisto, tão logo haja alterações na legislação concernente.

Quanto ao projeto de pesquisa apresentado pelo candidato no momento de sua inscrição à seleção, considera-se que os candidatos nem sempre conhecem as linhas de pesquisa da instituição sede do curso, e devendo ser esclarecidos que suas futuras teses terão que estar relacionadas com essas linhas, pois os orientadores disponíveis trabalham em temas pertinentes àquelas em que estão inseridos. Assim, os pretendentes devem saber que o fato de serem selecionados para o curso, não obriga a faculdade a aceitar seu projeto como de futura tese e que o mesmo será apreciado, apenas, como mero exercício acadêmico de planejar e defender um projeto de investigação. Este aspecto protege, também, a liberdade do candidato de procurar outra instituição, no caso de desejar realizar a sua tese de doutorado com base no projeto elaborado. Para a avaliação do projeto de pesquisa, são pontuados os seguintes aspectos:

a) Que o problema ou questão norteadora da investigação valorize as soluções para os problemas de enfermagem ou consista em uma proposição solucionadora. A enfermagem enfrenta inúmeros problemas bem conhecidos dos profissionais que para serem solucionados exigem muita pesquisa, trabalho e criatividade. O fato do curso de doutorado estar organizado em uma instituição financiada pelos cofres públicos implica na responsabilidade de oferecer à nossa sociedade um trabalho comprometido com o seu bem-estar, tendo em vista a carência e urgência de nossa população. Mesmo no caso de faculdades particulares, o compromisso social da profissão leva a considerar desejável, que sejam priorizados trabalhos que se detenham nas soluções ou nas proposições para a problemática da comunidade.

b) Que apresente uma argumentação coerente sobre o referencial teórico do tema selecionado. Os candidatos a pesquisador, para desenvolverem trabalhos significativos, devem demonstrar preocupação com a profundidade do conhecimento necessário à pesquisa de alto nível de qualidade.

c) Que o tema seja coerente com a linha de atividades definida pelo "curriculum vitae". Se o tema estiver relacionado com sua linha de atividades, a coerência da argumentação, analisada no item anterior, deverá destacar-se.

d) Que demonstre conhecimento da metodologia escolhida e seja capaz de argumentar a favor de sua opção. A metodologia selecionada deverá estar adequada 
ao problema ou questão central do projeto e o candidato deverá saber argumentar sobre sua opção e discuti-la.

Como o estabelecimento de critérios quantitativos, para o julgamento do projeto é extremamente difícil, cada membro da comissão de seleção (de 2 a 3 elementos) pode analisá-lo e atribuir de 0 a 4 pontos. Posteriormente, em conjunto, pode-se chegar a uma só pontuação para cada projeto, com aceitação unânime dos membros selecionadores ou por meio de médias aritméticas. A nossa experiência tem mostrado que não existem grandes disparidades no julgamento dos projetos pelos membros envolvidos e que não é difícil chegar-se a um consenso. Essa pontuação pode ser multiplicada por 10 para que, quando somada à pontuação recebida pelo candidato no curriculum, contribua com $40 \%$ do total da pontuação (ao invés de $4 \%$ ).

A pontuação final do candidato é igual à soma da pontuação obtida no curriculum com aquela originada da análise do projeto de pesquisa, dividida por dois.

Finalmente, a entrevista deve ser realizada pelos membros da comissão cujo número deve variar entre 2 e 3 elementos. Ela deve respeitar os seguintes cuidados:

- deixar o candidato à vontade e comodamente instalado;

- apresentar todos os membros entrevistadores;

- dar oportunidade ao candidato para explanar e defender seu projeto de pesquisa, a fim de que demonstre sua capacidade de exposição oral e comprove a autoria de seu projeto;

- fazer, também, perguntas de forma a clarear aspectos do curriculum e dos projetos do candidato sobre as atividades que pretende desenvolver após o doutorado;

- não ultrapassar o tempo de 30 minutos;

- os mesmos entrevistadores devem entrevistar todos os candidatos para terem parâmetros de referência e poderem comparar o desempenho dos mesmos.

A pontuação da entrevista deve ser dada apenas nos casos em que o desempenho do candidato não reforce a pontuação final por ele obtida no curriculum e no projeto. Assim, um candidato que, durante a entrevista, supere as expectativas, pode merecer de 1 a 3 pontos acrescidos à média final. Por outro lado, o candidato que demonstrar muita inconsistência na defesa oral do projeto ou do curriculum, pode ter rebaixada sua pontuação final de 1 a 3 pontos.

A decisão sobre a utilização ou não da pontuação acima referida, depende do consenso dos entrevistadores.

Com base na pontuação total, pode-se elaborar uma lista com a classificação dos candidatos, a qual, antes de ser divulgada, deve ser compartilhada e submetida ao colegiado que instituiu a comissão de seleção para análise e aprovação final da relação dos candidatos selecionados.

A análise da pontuação final levou-nos à constatação que um candidato pode receber, no máximo, cerca de 49 ou 50 pontos, nos casos em que o Mestrado é exigência 
para todos os candidatos. Para compor esse total de pontos, verificou-se que cada item contribui com a seguinte quota:

- o projeto de pesquisa $41 \%$

- a formação pós-graduada $2 \%$

- o dinamismo da atualização 8\%

- a experiência profissional $12 \%$

- a produção científica 33\%

- o tempo para a aposentadoria 4\%

Esses valores representam o peso de cada item na classificação final e parecem ser coerentes com os objetivos do curso e com a filosofia expressa neste trabalho. Contudo, lembramos aos leitores que os valores podem e devem ser alterados em função da política e filosofia da instituição.

A título de conclusão, reafirmamos nosso interesse em oferecer uma sugestão para servir de base aos futuros processos de seleção aos cursos de doutorado do país. De forma alguma, pretendemos dizer que seja a melhor ou a única forma de se selecionar candidatos, pois, como ZIEMER et al. (1992) afirmam, os requisitos para a admissão aos cursos podem ser muito variados. É, somente, uma alternativa que poderá auxiliar aqueles docentes encarregados da difícil tarefa de selecionar candidatos e que, como nós, estão sempre à procura de novas e melhores formas de realizar suas tarefas.

Chamamos a atenção do leitor para o fato da presente sugestão de seleção priorizar aqueles enfermeiros dedicados à docência, não só por valorizar a experiência em ensino superior como, também, por pontuar com peso três a produção científica, a qual encontra, na universidade, maiores oportunidades e melhores condições de realização.

\section{REFERÊNCIAS BIBLIOGRÁFICAS}

01. FRIEDLANDER, M. R.; STEFANELLI, M. C. Pós-Graduação: como pensamos atualmente. USP - Escola de Enfermagem - Boletim Informativo. São Paulo, v. 3, n. 4, p. 2, jul/ago, 1992.

02. LASH, A. A. Rival conceptions in doctoral education in nursing and their outcomes: an update. Journal of Nursing Education, v. 26, n. 6, p. 221-27, Jun. 1987.

03. MENDES, A. I. Doctoral education in nursing: its present and its future. Journal of Professional Nursing, v. 4, n. 6, p. 436-46, Nov/Dec. 1988.

04. SNYDER- HALPERN, R. Nursing doctorates: is there a difference? Nursing Outlook, v. 34, n. 6, p. 284-85, Nov/Dec. 1986.

05. STEFANELLI, M.C.; FRIEDLANDER, M.R. Importancia de los programas de Post-Grado para el desarrollo técnico-científico de enfermería. PRODEN, reunión desarrollo de Enfermería Latino-Americana. Belo Horizonte: Universidade Federal de Minas Gerais, 1992.

06. ZIEMER, M. M.; BROWN, J.; FITZPATRICK, M. L.; MANFREDI, C.; O'LEARY, J.; VALIGA, T. M. Doctoral programs in nursing: philosophy, curricula, and program requirements: Journal of Professional Nursing, v. 8, n.1, p. 56-62, Jan/Feb, 1992. 